\title{
Mosquito inspired medical needles
}

Lenau, Torben Anker; Hesselberg, Thomas; Drakidis, Alexandros Dimitrios; Silva, Patricia ; Gomes, Silvana

Published in:

SPIE Conference on Bioinspiration, Biomimetics, and Bioreplication 2017

Link to article, DOI:

$10.1117 / 12.2261399$

Publication date:

2017

Document Version

Publisher's PDF, also known as Version of record

Link back to DTU Orbit

Citation (APA):

Lenau, T. A., Hesselberg, T., Drakidis, A. D., Silva, P., \& Gomes, S. (2017). Mosquito inspired medical needles. In M. Knez, A. Lakhtakia, \& R. J. Martín-Palma (Eds.), SPIE Conference on Bioinspiration, Biomimetics, and Bioreplication 2017 (Vol. 10162). [1016208] SPIE - International Society for Optical Engineering. https://doi.org/10.1117/12.2261399

\section{General rights}

Copyright and moral rights for the publications made accessible in the public portal are retained by the authors and/or other copyright owners and it is a condition of accessing publications that users recognise and abide by the legal requirements associated with these rights.

- Users may download and print one copy of any publication from the public portal for the purpose of private study or research.

- You may not further distribute the material or use it for any profit-making activity or commercial gain

- You may freely distribute the URL identifying the publication in the public portal

If you believe that this document breaches copyright please contact us providing details, and we will remove access to the work immediately and investigate your claim 


\title{
Mosquito inspired medical needles
}

\author{
Torben A. Lenau ${ }^{*}$, Thomas Hesselberg ${ }^{b}$, Alexandros Drakidis ${ }^{\mathrm{a}}$, Patricia Silva ${ }^{\mathrm{a}}$, Silvana Gomes ${ }^{\mathrm{a}}$ \\ ${ }^{\mathrm{a}}$ Technical University of Denmark, Dept. of Mechanical Engineering, \\ Produktionstorvet b. 426B DK-2800 Kgs. Lyngby; \\ ${ }^{b}$ University of Oxford, Dept. of Zoology, South Parks Road, Oxford, OX13PS, United Kingdom.
}

\begin{abstract}
The stinging proboscis in mosquitos have diameters of only 40-100 $\mu \mathrm{m}$ which is much less than the thinnest medical needles and the mechanics of these natural stinging mechanisms have therefore attracted attention amongst developers of injection devises. The mosquito use a range of different strategies to lower the required penetration force hence allowing a thinner and less stiff proboscis structure. Earlier studies of the mosquito proboscis insertion strategies have shown how each of the single strategies reduces the required penetration force. The present paper gives an overview of the advanced set of mechanisms that allow the mosquito to penetrate human skin and also presents other biological mechanisms that facilitate skin penetration. Results from experiments in a skin mimic using biomimetic equivalents to the natural mechanisms are presented. This includes skin stretching, insertion speed and vibration. Combining slow insertion speed with skin tension and slow vibration reduces the penetration force with $40 \%$.
\end{abstract}

Keywords: Medical needles, skin penetration, biomimetics

\section{INTRODUCTION}

The present research project is motivated by the wish to produce medical needles from polymer material. Polymer needles will enable new types of innovative medical treatments and improve the quality of existing treatments. In contrast to steel needles polymer needles offer a range of highly interesting added functionalities enabling new biomedical and biotechnological solutions. Polymer needles can be used within MRI-scanners to allow for the use of very short lived and non-toxic tracers such as hyperpolarized metabolic contrast agents ${ }^{1}$. This will enable accurate identification of small cancer metastases within MRI-scanning. Another advantage is that the needles can be made transparent enabling direct photonic analyses of chemical indicators in the body in combination with the medical injection. Needles can furthermore be made so they have two or more delivery channels allowing simultaneous delivery of reactive agents such as two component chemotherapy. This makes much more precise medication possible where active components can be injected with high accuracy. The needles are also much easier to de-activate which makes them easier to dispose of. The latter is likely to become an important issue with the growing use of needles outside hospitals.

However, there is a major challenge with using polymer needles: They are much softer than steel making skin penetration difficult. The stiffness measured as Young's modulus is for most polymers are a factor 100 lower than steel. This gives two problems when injecting needles. A long slender needle buckles easily and the needle tip bends or flattens which increases tip area and hence the required penetration force.

Nature has many examples of advanced penetration mechanisms where apparently soft materials succeed in penetrating skin. The mosquito being one of the more well-known and at the same time most advanced. The explanation of how this is possible is a combination of applied penetration strategies, which on the one hand reduces the required force for penetrating skin and on the other hand increases the effective stiffness of the penetrating organ.

This paper gives an overview of selected biological strategies for skin penetration and of the detailed strategies that enable mosquitos and other stinging and biting insects to pass the skin barrier. Three of the strategies namely skin strain, vibration and insertion speed is further examined in an experimental setup. In contrast to earlier studies we also examine the effect of combining the penetration force reducing strategies.

*1enau@dtu.dk; phone +45 4525 4811; mek.dtu.dk

Bioinspiration, Biomimetics, and Bioreplication 2017, edited by Mato Knez, Akhlesh Lakhtakia, Raúl J. Martín-Palma Proc. of SPIE Vol. 10162, 1016208 · @ 2017 SPIE · CCC code: 0277-786X/17/\$18 · doi: 10.1117/12.2261399 


\subsection{Skin penetration in nature}

A range of different organisms have evolved mechanisms allowing them to penetrate the skin of mammals. Here we focus on organisms capable of penetrating the human skin with slender tube-like structures as these have the largest biomimetic potential for the development of micro-needles. We therefore ignore the large number of animals capable of biting through human skin with teeth as this typically cause too much tissue damage to provide any benefits in the development of medical needles. We divide the mechanisms into three separate categories; spine-like structures that have evolved as a defense-mechanisms to penetrate the skin causing maximum mechanical damage, spines and stingers that have evolved to penetrate the skin and inject toxins, slender mouthparts that have evolved to both inject anticoagulants, to extract blood and to efficiently withdraw the mouthparts. For each of the three categories we provide a couple of examples.

\subsection{Penetration only}

A number of plants and animals have evolved defensive spines to deter mammalian herbivores or predators, including humans, to attack them. Cacti is a group of spiny plants that are particularly well-known for their large number of sharp spines arising from modified leaves and capable of inflecting significant pain to any mammals attempting to eat or collect them. Their main function is to protect the plant against herbivores although some also protect against temperature stress ${ }^{2}$. Spines of Opuntia ficus-indica consist of around $50 \%$ cellulose and $50 \%$ hemicellulose in the form of the polysaccharide arabinan with a small amount of lignin, fat and waxes as well ${ }^{3}$. The cellulose is organized in internal fibres running along the length of the spines to provide high bending strength, while the external surface of the spines consists of cuticle cell that gives it a rough appearance ${ }^{3}$. The spines are typically about $25 \mathrm{~mm}$ long with a diameter of $0.2 \mathrm{~mm}$ and at the end tapers into a sharp rigid tip. Similar properties are found in other cacti although there is variation in spine morphology. In the Turbinicarpus, the spines show particular large variations in size, number, shape and texture with external surfaces being smooth, rough, with regular short protrusions or with longer hair-like structures and with varying degree of stiffness ${ }^{4}$. All stiff spines, independent of what external surface, invariable have a sharp rigid tip.

The animal equivalents to cacti are the hedgehogs (belonging to the mammalian order Eulipotyphla) and the porcupines (belonging to the order Rodentia), which are both covered in long spines. In porcupines, these are commonly referred to as quills. While the spines and quills are superficially quite similar with both being slender, hollow keratin structures tapering to a sharp point, quills are significantly longer (up $144 \mathrm{~mm}$ long with a diameter of $4.8 \mathrm{~mm}$ ) than hedgehog spines $(21 \mathrm{~mm} \text { long with a } 1.2 \mathrm{~mm} \text { diameter })^{5}$. The mechanical properties of the two are also different with quills having evolved to be as straight and stiff as possible without buckling too easily, while hedgehog spines are slightly curved and can buckle elastically allowing them to take a higher load and possibly absorb elastic energy from falls $\mathrm{s}^{5}$. Hedgehog spines have smooth surfaces, whereas most quills have backward facing barbs on their surface ${ }^{6}$. Interestingly, quills with barbs require up to $50 \%$ less penetration force into bird muscle tissue than barbless quills, presumably because the high stress concentrations near the barbs reduce the need to deform the entire circumference of the surrounding tissue ${ }^{7}$.

\subsection{Penetration and injection}

Mechanical damage from stiff spines work well as an immediate deterrent to attack, but some plants and animals have evolved more potent defenses and inject toxic substances into the tissue after penetration. Some caterpillars, for example, have hollow spines connected to a poison sac. Caterpillars of the Parasa consocia moth have spines that are about 500$700 \mu \mathrm{m}$ long and 30-35 $\mu \mathrm{m}$ in diameter with the external surface possessing backward facing barbs in low densities ${ }^{8}$. The mean penetration force of five spines into mouse skin was found to be as low as $0.2 \mathrm{mN}$, which the authors mainly ascribed to high stiffness (low risk of buckling failure) and an ultra-sharp tip ${ }^{8}$.

More well-known and more aggressively defensive, however, are the social hymenopterans such as the honey bee. The individual workers do not reproduce and will therefore mount a very determined defense of the queen and the hive. When honeybees sting larger animals such as mammals and humans, they sacrifice their own life as the stingers and part of the abdomen with the poison sac remains in their victim when the bee pulls away. The stinger of the honeybee Apis cerana cerana is about $1.8 \mathrm{~mm}$ long with a diameter of $50 \mu \mathrm{m}$ and consists of an unpaired stylet and paired lancets ${ }^{9}$. The tips of the lancets are ultra-sharp and both stylet and lancets contain relatively long (up to $13 \mu \mathrm{m}$ ) backward facing barbs. The penetration force of stingers into artificial skin was measured to be around $0.6 \mathrm{mN}$, whereas the barbs acting as hooks into the tissue meant that the withdrawal force was almost 260 times higher'. 


\subsection{Penetration, injection and withdrawal}

Haematophagy (feeding on blood) has evolved in a number of different species, although predominantly in insects (see Table 1 for a list of haematophagous animals specializing on human blood). Blood is nutritious source of proteins and saccharides which can be obtained relatively effortless. Haematophagy is particularly interesting from a biomimetic perspective, because it involves ectoparasites using specialized mouthparts to penetrate skin, extract liquid and withdraw their feeding apparatus afterwards covering the same stages medicine injection or taking blood samples require. In addition, there has been strong selection on the animals to inflict as little pain as possible on the host to avoid host defenses such as removing or killing the parasite becoming activated ${ }^{10}$. Table 1 provides an overview of the major haematophagous parasites capable of extracting blood from humans, but here we focus on two of the most important and best studied groups; the ticks and the mosquitoes.

Table 1: List of haematophageous animals that feed on human blood

\begin{tabular}{|l|l|l|l|}
\hline & Taxonomic order & Taxonomic family & Number of species* \\
\hline Insects: & & & \\
\hline Mosquitoes & Diptera & Culicidae & $>100$ \\
\hline Tetseflies & Diptera & Glossinidae & 6 \\
\hline Sandflies & Diptera & Psychodidae & 70 \\
\hline Horse and deer flies & Diptera & Tabanidae & $>100$ \\
\hline Biting midges & Diptera & Ceratopogonidae & $<10$ \\
\hline Fleas & Siphonaptera & Pulicidae & 1 \\
\hline Lice & Phthiraptera & Pediculidae, Pthiridae & 3 \\
\hline Assassin bugs & Hemiptera & Reduviidae & $>100$ \\
\hline Bed bugs & Hemiptera & Cimicidae & 1 \\
\hline & & & \\
\hline Other animals: & & & 6 \\
\hline Medicinal leeches & Hirudinida & Hirundinidae & 3 \\
\hline Vampire bats & Chiroptera & Phyllostomidae & $>20$ \\
\hline Ticks & Ixodida & Ixodoidae & \\
\hline
\end{tabular}

*An approximate number of species that are obligate or opportunistic parasites of humans. Most orders/families contains a much larger number of species specialising on other mammals and vertebrates.

Ticks are a form of ectoparasitic mites that attach firmly to their hosts and feed for several days. It is during this time that the tick can infect its human host with Lyme disease, which is caused by bacteria that transfers from the tick to the human after feeding has lasted for more 36 hours. The penetrating mouthparts of the Ixodes ricinus tick consist of a ventral hypostome about $0.36 \mathrm{~mm}$ long and $0.14 \mathrm{~mm}$ wide and a pair of chelicerae of similar length but half of the width $^{11}$. The chelicerae end in sharp tips that provide the first penetration into the skin, where after the two chelicerae flex into a V-like form that firmly attach them to the tissue as the hypostome extends. The hypostome has large teeth along both edges and through a series of ratched-like extensions 'saw' its way into the tissue ${ }^{11}$. Interestingly both the chelicarae and the hypostome contains numerous barbs that might facilitate easier penetration into the skin similar to the barbs on the porcupine quills discussed above, although the tick mouthparts allow a much more dynamic and flexible interaction with the host tissue ${ }^{11}$.

Without doubt the most well-known and best studied hamaetophagous animal is the mosquito. It is also one of the deadliest animals in the world as several species of mosquitoes are carries for the protozoan Plasmodium falciparum, 
which causes malaria. Malaria affects more than 200 million people annually and causes almost half a million deaths per year. In addition, mosquitoes are transmitting a range of other diseases including dengue, West Nile virus and yellow fever. While individual mosquito species usually specialise on a specific host species most attack multiple hosts and while some species are particularly anthropophilic such as Anopheles gambiae, one of the main carriers of malaria, and Aedes egypti, the main carrier of dengue and yellow fever, others are opportunists and shifts to humans when the opportunity arise ${ }^{10}$. Mosquitoes are attracted to their host over long distances via $\mathrm{CO}_{2}$ and odour emissions from the host and once they are close to the host a combination of odour cues, temperature and species specific preferences for specific body parts guide them to the biting site $^{12}$. In the next section, we provide more details on the mechanics of skin penetration in mosquitoes.

\subsection{Skin penetration in mosquitoes}

The mosquito proboscis (the stinging organ) is a specialized variant of the ancestral insect biting mouth parts. It is a delicate mechanism consisting of 7 elements ${ }^{13,14}$ as illustrated in figure 1 . Outermost is the labium, which like a sheath covers the other 6 elements that together forms the fascicle to be inserted into the skin. The labium has the form of a sliced tube allowing it to open and bend away from the fascicle as it is inserted into the skin. The tip of the labium has two flaps that are pushed to each side when the proboscis is pushed towards the skin causing the skin to stretch. The 6 elements in the fascicle are the labrum (a relatively large tube used for transporting blood with sharp projections at the tip), the hypopharynx (a small diameter vessel used for injecting blood thinning saliva), two maxillae (stylets with serrations on the side) and two mandibles (pointed stylets). The fascicle of Aedes albopictus is about 1.5 to $2.5 \mathrm{~mm}$ in length and $20-40 \mu \mathrm{m}$ in diameter ${ }^{13}$.
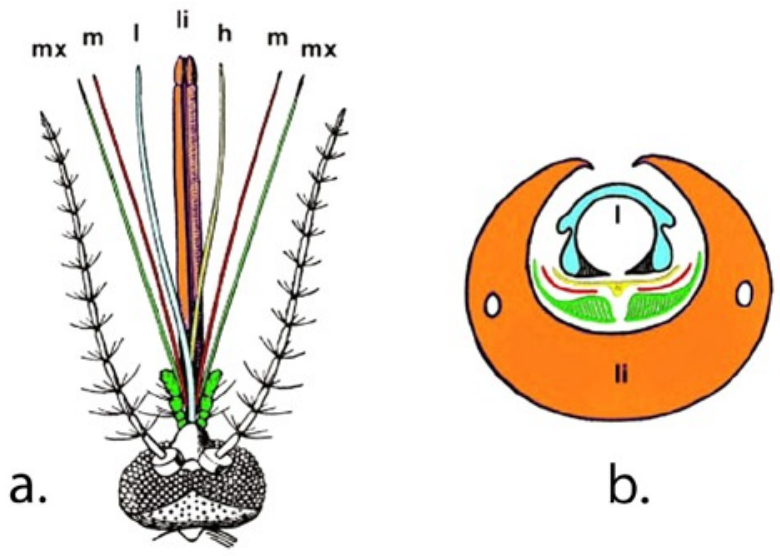

Figure 1. The mosquito proboscis: Seen from above (a) and cross section (b). li: labium, 1: labrum, h: hypopharynx, m: mandible, mx: maxilla

Ramasubramanian et al. explains the sequence of actions for mosquito stinging as follows ${ }^{15}$. After landing on the skin the mosquito search for a suitable injection place by poking its proboscis. The tip of the labrum together with the mandibles are the first to enter the skin and Kong and $\mathrm{Wu}$ found that the mean penetration force of only $18 \mu \mathrm{N}$ for Aedes albopictus penetrating $\operatorname{skin}^{13}$. The process is very adaptive where the mosquito compensates for unwanted bending. The facile is anchored, i.e. the tip penetrate the outermost layer of the skin and the facile is repeatedly pushed forth and back within the labium at a frequency around $15 \mathrm{~Hz}^{15}$. As the facile progresses through the skin and becomes more stable due to a shorter free length the vibration is reduced to around $6 \mathrm{~Hz}$. The serrated maxillae appear to 'saw' the fascicle deeper into the skin in a similar manner to the tick hypostome discussed in the previous section ${ }^{13}$. Aoyagi et al. describes how the labium bends as the facile penetrates the skin and they observed a higher frequency of $30 \mathrm{~Hz}$ during insertion. They also noticed that as the labrum bended the tip of the labrum opened and closed giving tension to the $\operatorname{skin}^{14}$. Choumet measured the duration of the stinging process for a Anopheles gambiae mosquito and found median probing time to be $142 \mathrm{~s}$ and median feeding time to be $240 \mathrm{~s}^{16}$. The stinging process can therefore be considered rather slow. 


\section{SKIN PENETRATION STRATEGIES}

Animal skin consist of several layers ${ }^{17}$. The outermost layer is the epidermis which is covered with stratum corneum which consists of dead tissue cells. It is the hardest and toughest part of the skin and also the part that is most difficult to penetrate. Under the epidermis there are the dermis and subcutis which is a fatty layer. Needle injection experiments often apply an artificial skin model using a tough elastomer such as silicone rubber, latex or polyurethane as an equivalent to the stratum corneum layer and a gel to mimic the softer underlying layers.

Penetrating skin involves at least two distinct activities: The initial making of a hole and the insertion of the stinging organ. The present paper focus on the first activity where the challenge is to maintain the pointed tip geometry ensuring a high fracture stress. This can be achieved by reducing the skin resistance or by improving the penetration tool itself. Another big challenge is to avoid buckling of a slender tube, i.e. the lateral deflection of the tube when the axial compression force exceeds a critical load - but this is not dealt with in this paper. Sakes et al provide an extensive review of buckling reducing strategies in nature ${ }^{18}$.

\subsection{Reducing skin resistance}

Applying different strategies can change skin properties. These include skin insertion speed, tension, vibration and skin hydration.

Insertion speed impacts insertion characteristics, but results from different sources point in opposite directions. Van Gerven et al. reviewed a number of studies and found that higher velocities tend to decrease puncture force and increase friction for biological materials while the opposite seems to be the case for artificial materials ${ }^{19}$. Mahvash et al. found that increased velocity lead to lower forces when injecting a needle into a porcine heart using velocities between 1 and $250 \mathrm{~mm} / \mathrm{s}^{20}$. Hing et al. measured lower forces at higher velocities using a porcine liver at velocities between 1 and 25 $\mathrm{mm} / \mathrm{s}^{21}$. Crouch et al. reports increasing force for higher velocities when injecting in a silicone gel at speeds between 3 and $21 \mathrm{~mm} / \mathrm{s}^{22}$. Webster et al found that increasing insertion velocity lead to higher insertion forces when using a rubberlike skin model and insertion velocities between 5 and $25 \mathrm{~mm} / \mathrm{s}^{23}$.

Stretching skin has an effect on the skin penetration force. The tip of the labium of the mosquito splits as the proboscis is pressed towards the $\operatorname{skin}^{14}$. The labium therefore stretches the skin increasing the skin tension in the penetration area. Aoyagi et al. ${ }^{14}$ mimicked the skin tensioning by stretching a silicone rubber strip and injecting a needle (needle width $230 \mu \mathrm{m}$ ) with and without the tensioning. With an applied $6 \%$ strain the penetration force was $0.3 \mathrm{~N}$ compared to $0.4 \mathrm{~N}$ without the strain. This is equivalent to $25 \%$ decrease in penetration force.

Vibration affects the skin by provoking a shear thinning effect referred to as thixotropy ${ }^{18}$. When at rest ordered microstructures in the skin give a relative stiffness but when shaken the microstructures becomes more unstructured giving a more viscous and less stiff characteristic ${ }^{24}$. There are several examples of how vibration reduces the force required to penetrate skin.

Ramasubramanian et al. studied a mosquito having a ca. $2 \mathrm{~mm}$ long proboscis using a high-speed camera and found that a longitudinal oscillation of around $15 \mathrm{~Hz}$ is used in the beginning of the insertion. When the proboscis is half way into the skin, the vibration is reduced to ca. $6 \mathrm{~Hz}$. Izumi made a similar observation and reports a frequency of several dozen $\mathrm{Hz}^{25}$. Yang reports $200-400 \mathrm{~Hz}$ vibration in mosquitos ${ }^{26}$ but did not measure it or provide a reference.

Muralidharan found significant reduction in penetration force using longitudinally vibration ${ }^{27}$. Two skin models were used: A chicken ventriculus and a skin mimic made from latex and clay. Using amplitude of $0.03 \mathrm{~mm}$ and a frequency between $0-1000 \mathrm{~Hz}$ penetration forces varied for a diameter of $0.51 \mathrm{~mm}$ needle between $0.23 \mathrm{~N}$ and $0.51 \mathrm{~N}$ for the chicken model and between $0.77 \mathrm{~N}$ and $1.43 \mathrm{~N}$ for the skin mimic. The lowest penetration force was found for the highest frequencies, but the most drastic reduction in penetration force was for very slow vibrations (a reduction from $1.4 \mathrm{~N}$ to $1.05 \mathrm{~N}$ going from 0 to $1 \mathrm{~Hz}$ ).

Yang et al. found a $70 \%$ reduction (from $0.26 \mathrm{~N}$ to $0.08 \mathrm{~N}$ ) for a $0.1 \mathrm{~mm}$ diameter silicon needle in penetration force using lateral vibration using an amplitude of $0.6 \mathrm{~mm}$ and $\mathrm{kHz}$ frequency in animal tissue ${ }^{26}$. Izumi also used a micro-fabricated silicon needle using $30 \mathrm{~Hz}$ vibration and an amplitude of $140 \mu \mathrm{m}$ with a penetration force around $0.1 \mathrm{~N}$ in silicon rubber skin model. In a similar study Aoyagi et al. used $30 \mathrm{~Hz}$ and amplitude of $8 \mu \mathrm{m}$ resulting in a force reduction from $0.4 \mathrm{~N}$ to $0.3 \mathrm{~N}$. 
Hydration also has an effect on the mechanical properties of skin. Wildnauer investigated the role of relative humidity on $\operatorname{skin}^{28}$. The experiments were made on the stratum corneum i.e. the outer most layer of the skin. It was found that humidity had a noticeable effect on ultimate strength and elongation. When relative humidity was increased from 0 to 100 the ultimate strength was reduced from $0.5 \mathrm{~N}$ to $0.1 \mathrm{~N}$ and elongation was increased from $20 \%$ to $200 \%$.

\subsection{Improve the penetration tools}

The shape of the penetration tool has an impact on the resulting penetration force. Aoyagi ${ }^{14}$ found that a more pointed tip had lower penetration force. They examined 4 angles: 15, 30, 45 1nd 75 degrees. A 15-degree needle tip had three times as low penetration force compared to a needle with 75-degree tip. Another factor is dynamic loading. If the load duration becomes sufficiently small the impulse load becomes more important than the static load ${ }^{18}$. This means that the needle will become less sensitive to buckling and a lower penetration force since the substrate is prevented movement and deformation. The tip geometry also has an impact on the penetration load where beveled, conical and diamond shapes performs differently ${ }^{18}$.

\section{TESTING PENETRATION STRATEGIES}

As described above, there are a number of different strategies for making skin penetration easier. We have chosen to experimentally validate three of the strategies and if the superposition principle applies to a combination of these results, i.e. if the effect of each of the strategies can be added together when applied simultaneously. We therefore have 4 hypotheses:

1) Increased insertion velocity increases penetration force.

2) Higher skin tension will up to a certain threshold reduce penetration force.

3) Penetration force can be reduced using vibration.

4) A combination of two or three penetration strategies will reduce the penetration force adding together the effect from each strategy.

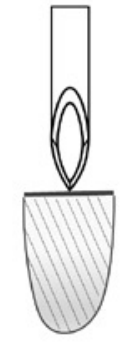

a

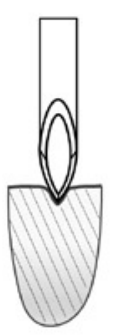

b

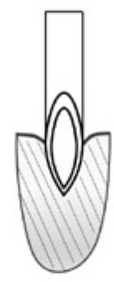

c

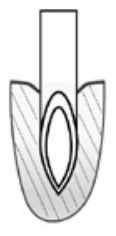

d

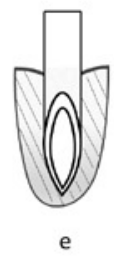

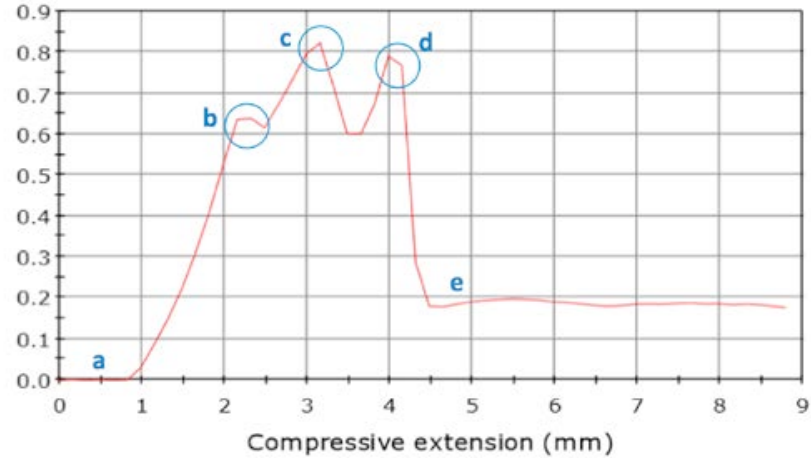

Compressive extension $(\mathrm{mm})$

Figure 2 Basic phases in needle insertion: a) no interaction, b) boundary displacement and penetration of the tip, c) tip is halfway inserted, d) tip is fully inserted e) tip and shaft insertion. The graph at right shows a typical curve for penetration force. The unit for the vertical axis is force $(\mathrm{N})$.

To examine if a strategy has a positive impact on ease of insertion the following experimental setup was made. Metal needles were mounted in a material testing machine and inserted into a skin analogue while recording force acting axially on the needle and its velocity. The penetration force curve was recorded as the needle entered the skin model and the penetration force was found as point $b$ shown in figure 2. The figure illustrates that the needle first deflects the skin (from a to b), then puncture the skin at b, halfway at $\mathrm{c}$ there is a maximum where two grindings of the needle tip meet, at $\mathrm{d}$ the tip is fully inserted and at e the resistance mainly comes from friction. 


\subsection{Methods and materials}

A compression/tensile test machine 5940 Single Column from Instron was used for the experiments. The experimental setup is shown in figure 3. The mechanisms were explored experimentally using a standard skin model consisting of a polyurethane (PUR) strip and a gel ${ }^{29}$ shown in figure 4 . The fixture for the skin model is a polymer cube with a cylindrical hole. The hole contains the gel and the PUR-strip is placed over the gel. The PUR-strip was $18.7 \mathrm{~mm}$ wide and $0.38 \mathrm{~mm}$ thick. Young's modulus was measured to $20 \mathrm{MPa}$ using tensile testing. The strip is clamped in two sides making it possible to stretch the strip a controllable amount. Aligning marks on the PUR-strip with a ruler controls skin stretching as illustrated in the right-hand side of figure 3. A maximum strain value of 0.12 was chosen because Aoyagi et al. found close to lowest penetration forces for 0.06 strain.

The needles are 25G x 5/8" from BD Microlance coated with silicone. The luer connector was removed by heating to be able to mount it in the 3-jaw chuck. The needle was then cleaned using ethanol and it is therefore likely that the silicone lubricant is removed from the side of the needle. Needles were only used once in order to rule out the effect of a deformed tip.

Vibration was achieved by using a piezoelectric generator APA 400M from Cedrat Technologies as shown in figure 5 . The piezoelectric elements were placed inside a frame so that the resulting vibration dominantly was in the axial direction of the needle. Frequencies of $10 \mathrm{~Hz}$ and $30 \mathrm{~Hz}$ were chosen as these are similar to what the mosquito uses ${ }^{13,15}$. The amplitude was set to the lowest possible value which was calculated to be $10 \mu \mathrm{m}$ and the waveform was sinusoidal.

Each experiment was repeated 4 times. The following parameters were examined: Velocity $(0.2 ; 1.66 ; 3.12 \mathrm{~mm} / \mathrm{s})$, strain $(0 ; 0.3 ; 0.6 ; 0.12)$ and vibration $(0 ; 10 ; 30 \mathrm{~Hz})$. In total 120 experiments were made.

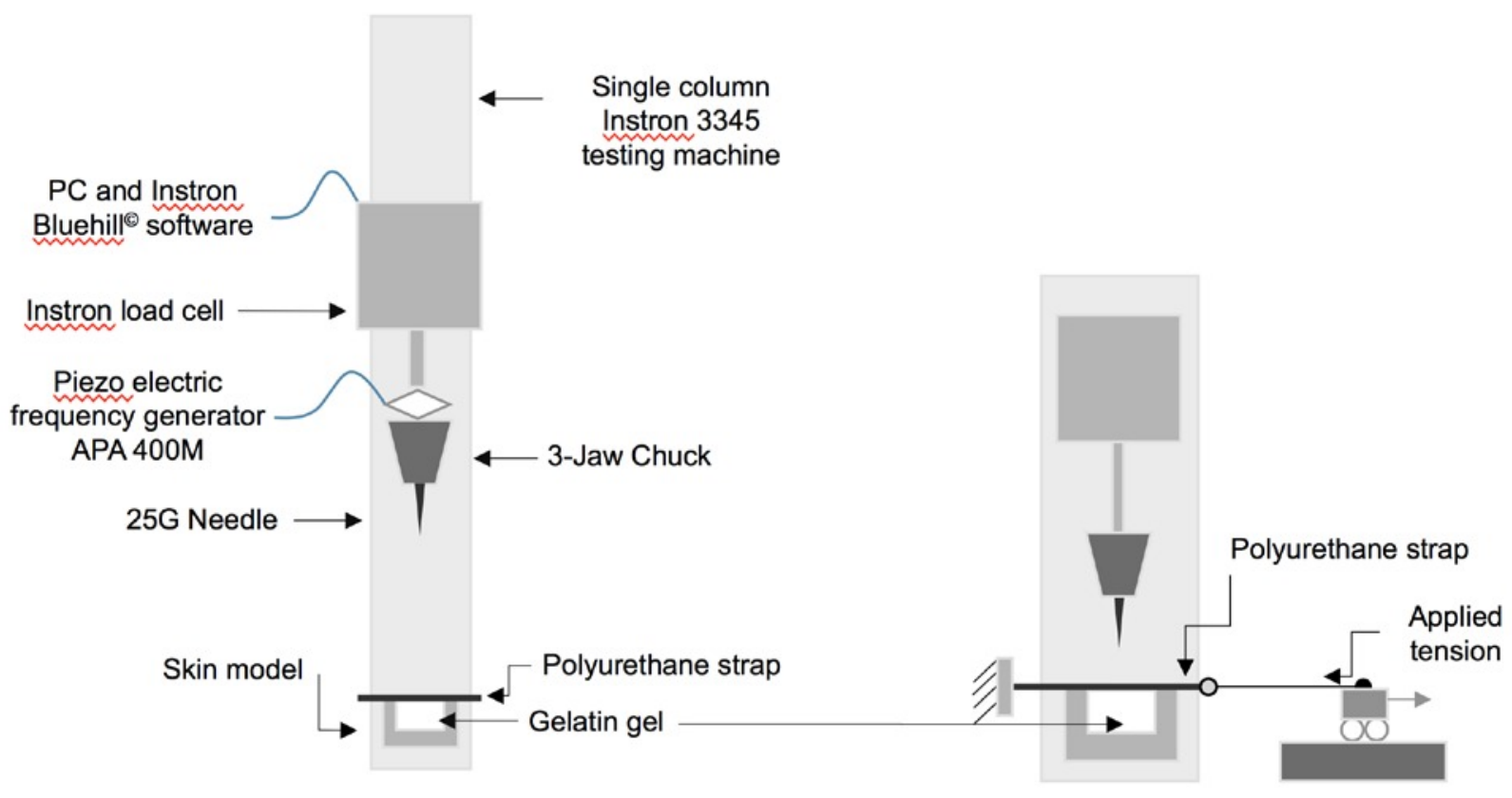

Figure 3: The experimental setup incl. the skin model and method for skin tensioning.

Mean values and standard deviations were calculated for each test series. The null hypothesis was that mean values for two datasets belonged to the same greater dataset and had the same mean. This was tested using a student T-test assuming normality and unequal variance for the two datasets. The T-test determines the probability of whether the means of the two datasets are equal. If the probability is low, e.g. lower that $5 \%$, it is unlikely that the two means are equal, or said in other words, it is likely that the two means are different. In our case the T-test is used to determine if the means of tests for different values of velocity, strain or vibration are different. We assume normality in the datasets, but since the sample sizes are small it can be difficult to tell and we therefore also used the non-parametric Wilcoxon's test 
that can be used on datasets that are not normally distributed. The statistics was calculated using the functions in Microsoft Excel 2016 and cross checked using the open source statistical software R from the Cran project.

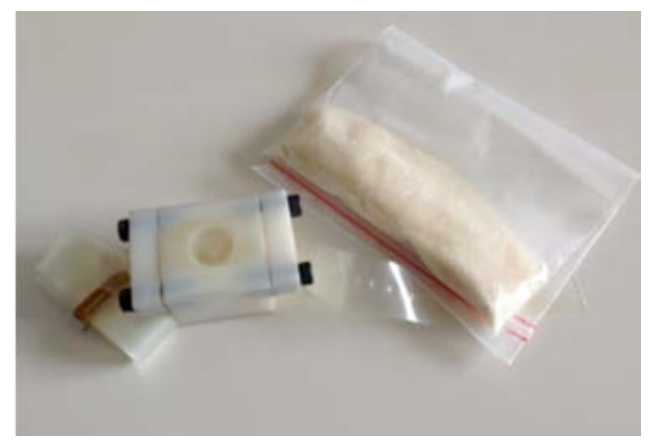

Figure 4: Skin model: gelatin powder, polyurethane membrane and polymer cube.

Figure 5: The vibration unit and the skin model.

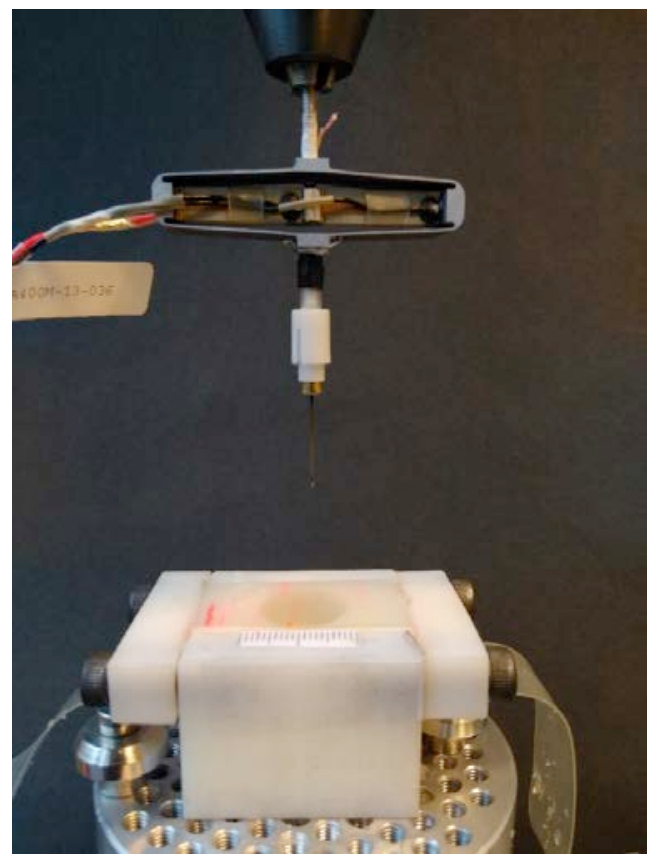

\subsection{Results}

Figure 6 describes penetration forces for different insertion velocities. The lowest penetration forces were found for low insertion velocity also when vibration and strain were applied. 


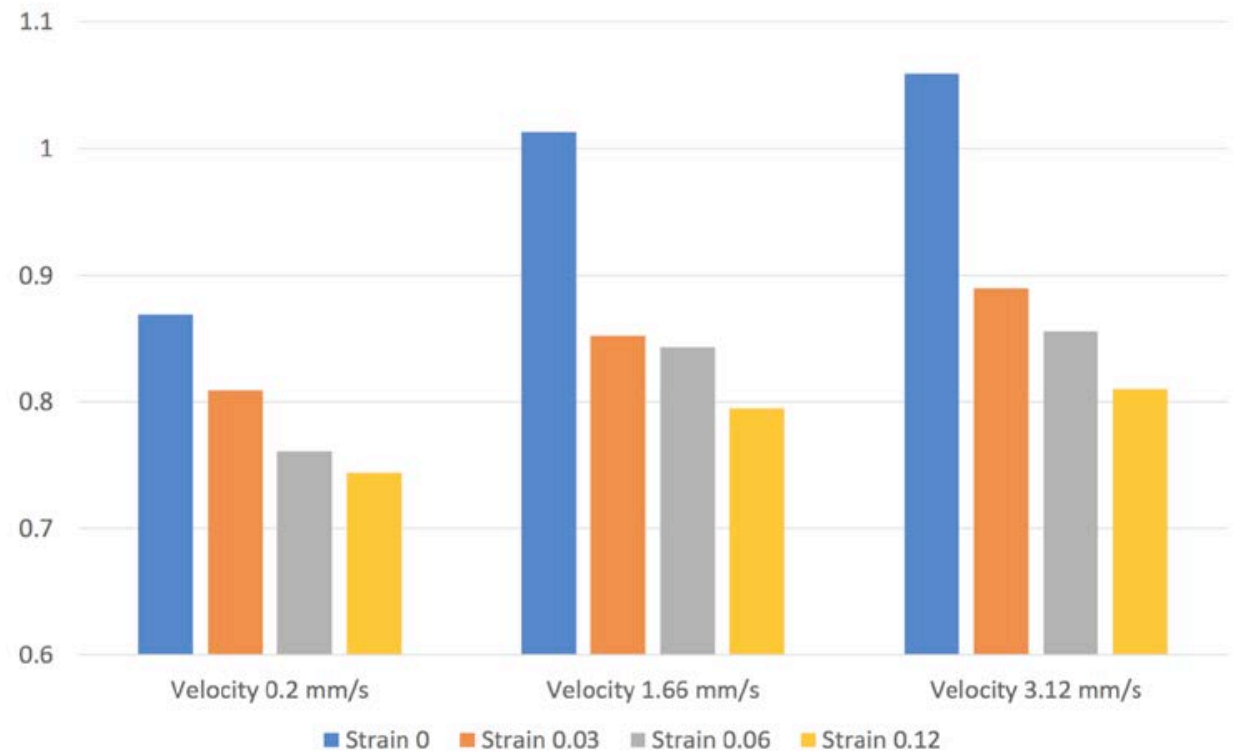

Figure 6 The role of skin strain (no unit) and velocity for penetration force (N)

As seen in figure 7 vibration and strain result in a lower penetration force. Strain alone reduces the penetration force with $14.7 \%$, vibration with $18.5 \%$ and the combination of the two with $31.4 \%$. Penetration force is reduced from $0.87 \mathrm{~N}$ to $0.6 \mathrm{~N}$ wich is $31.4 \%$. The experiments confirm that the superposition principle can be applied and the effect of the two strategies can be added together. A surprising finding is that best results $(0.71 \mathrm{~N})$ were found for vibrational frequencies of $10 \mathrm{~Hz}$ and that penetration forces increased for higher frequencies. Injection at higher frequencies up to $300 \mathrm{~Hz}$ were explored with a sample size of one showing penetration forces between $0.8 \mathrm{~N}$ and $0.9 \mathrm{~N}$.

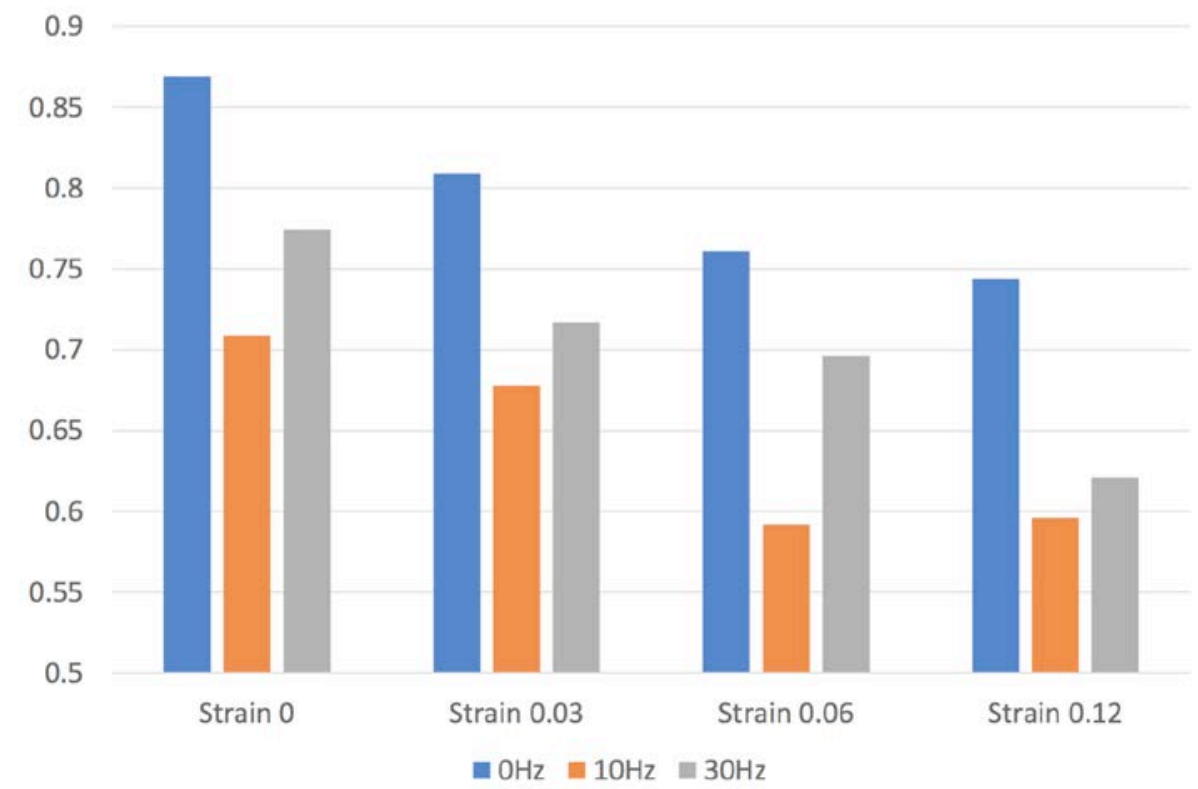

Figure 7 The role of skin strain (no unit) and vibration $(\mathrm{Hz})$ for penetration force $(\mathrm{N})$ at constant low velocity $(0.2 \mathrm{~mm} / \mathrm{s})$ 
The differences in mean values for each test series were tested statistically (see table 2) using t-test which in all cases except strain had $p$-values below 0.05 . The equivalent $p$-values using a Wilcinson test were larger: For velocity, strain and vibration the values were between 0.06 and 0.11 that is higher than the 0.05 treshold. For the combination of the three the value was 0.029 which was significant.

Table 2. Statistical values for penetration force for different values of velocity, strain and vibration.

\begin{tabular}{|c|c|c|c|c|}
\hline & mean & st.dev. & $\begin{array}{c}\text { p-value } \\
\text { (t-test) }\end{array}$ & $\begin{array}{c}\text { p-value } \\
\text { (wilcinson test) }\end{array}$ \\
\hline Velocity & & & & \\
\hline $0.2 \mathrm{~mm} / \mathrm{s}$ & 0.869 & 0.094 & & \\
\hline $3.2 \mathrm{~mm} / \mathrm{s}$ & 1.059 & 0.104 & 0.035 & 0.114 \\
\hline Strain & & & & \\
\hline 0 & 0.869 & 0.094 & & \\
\hline 0.12 & 0.742 & 0.033 & 0.067 & 0.057 \\
\hline Vibration & & & & \\
\hline $0 \mathrm{~Hz}$ & 0.869 & 0.094 & & \\
\hline $10 \mathrm{~Hz}$ & 0.709 & 0.070 & 0.037 & \\
\hline Strain + vibration & & & \\
\hline $0+0 \mathrm{~Hz}$ & 0.869 & 0.094 & & \\
\hline $0.12+10 \mathrm{~Hz}$ & 0.596 & 0.065 & 0.004 & 0.029 \\
\hline
\end{tabular}

\subsection{Discussion}

All three strategies for lowering penetration strategies namely velocity, strain and vibration had a noticeable effect. Furthermore, the experiments showed that the superposition principle applies and the effect of the single strategies can be added together. For injection velocity, we had best results for the slowest injection, which is similar to other authors that worked with artificial skin models but in contrast to many results from biological skin models (see table 3 for an overview). The skin model is off course important for the quality of the results. Human skin would give the results closest to reality, but for ethical reasons this is very difficult to work with. For this reason, a range of different models are used including animal tissue, latex, silicone rubber and PUR. It should be expected that animal tissue possess some of the same viscoelastic and thixitropic properties as human skin, even though other properties like stiffness can be quite different. Animal tissue is not homogeneous and larger sampling sizes are therefore required. For ease of access and predicted experimental conditions the artificial skin models are often preferred.

The experiments showed that strain reduces the penetration force. This is similar to earlier findings from other studies. Aoyaki et al. found a force reduction of $25 \%$ for $0.06 \operatorname{strain}^{14}$ but also that a higher strain did not reduce the force further. Our experiments showed the lowest forces ( $14.7 \%$ reduction) for a strain of 0.12 . Possible explanations could be due to the skin model. Aoyagi et al. used silicon rubber and we used PUR. 
Table 3. Force/velocity relationship from different sources

\begin{tabular}{|c|c|c|c|}
\hline Lowest force & Skin model & Velocity range & Source \\
\hline $\begin{array}{l}\text { Lower velocity } \\
\text { Higher velocity }\end{array}$ & $\begin{array}{c}\text { Artificial materials } \\
\text { Biological tissue }\end{array}$ & $\begin{array}{c}1-20 \mathrm{~mm} / \mathrm{s} \\
(1-20 \mathrm{~mm} / \mathrm{s})\end{array}$ & Van Gerven et al. ${ }^{19}$ \\
\hline Higher velocity & Porcine heart & $1-250 \mathrm{~mm} / \mathrm{s}$ & Mahvash et al. ${ }^{20}$ \\
\hline Higher velocity & Porcine liver & $1-25.4 \mathrm{~mm} / \mathrm{s}$ & Hing et al. ${ }^{21}$ \\
\hline Lower velocity & Silicone gel & $3-21 \mathrm{~mm} / \mathrm{s}$ & Crouch et al. ${ }^{22}$ \\
\hline Lover velocity & Rubber-like & $5-25 \mathrm{~mm} / \mathrm{s}$ & Webster et al. ${ }^{23}$ \\
\hline $\begin{array}{l}\text { Lower velocity } \\
\text { Lower velocity }\end{array}$ & $\begin{array}{c}\text { Latex }+ \text { clay } \\
\text { Soft chicken tissue }\end{array}$ & $\begin{array}{l}0.02-0.75 \mathrm{~mm} / \mathrm{s} \\
0.02-0.75 \mathrm{~mm} / \mathrm{s}\end{array}$ & $\begin{array}{l}\text { Muralidharan }{ }^{27} \\
\text { Obs: using } 100 \mathrm{~Hz} \\
\text { vibration }\end{array}$ \\
\hline Lower velocity & PUR strip + gel & $0.2-3.12 \mathrm{~mm} / \mathrm{s}$ & This paper \\
\hline
\end{tabular}

Table 4. Role of frequency in different sources

\begin{tabular}{|c|c|c|c|c|}
\hline $\begin{array}{l}\text { Frequency } \\
\qquad(\mathbf{H z})\end{array}$ & Amplitude $(\mu \mathrm{m})$ & Force (N) & Skin model & Source \\
\hline $\begin{array}{c}0 \\
1 \\
1000 \\
0 \\
1 \\
1000\end{array}$ & $\begin{array}{l}30 \\
30 \\
30 \\
30\end{array}$ & $\begin{array}{c}0.51 \\
0.35 \\
0.23 \\
1.4 \\
1.05 \\
0.77\end{array}$ & $\begin{array}{c}\text { Chicken ventriculus } \\
\text { Chicken ventriculus } \\
\text { Chicken ventriculus } \\
\text { Latex+clay } \\
\text { Latex+clay } \\
\text { Latex +clay }\end{array}$ & Muralidharan $^{27}$ \\
\hline $\begin{array}{c}0 \\
\mathrm{kHz}\end{array}$ & 600 (lateral) & $\begin{array}{l}0.26 \\
0.08\end{array}$ & Animal tissue & Yang et al. ${ }^{26}$ \\
\hline $\begin{array}{c}0 \\
30\end{array}$ & 140 & $\begin{array}{c}0.22 \\
0.1\end{array}$ & Silicon rubber & Izumi et al. $^{25}$ \\
\hline $\begin{array}{c}0 \\
30\end{array}$ & 8 & $\begin{array}{l}0.4 \\
0.3\end{array}$ & Silicon rubber & Aoyagi et al. ${ }^{14}$ \\
\hline $\begin{array}{c}0 \\
10 \\
30\end{array}$ & $\begin{array}{l}10 \\
10\end{array}$ & $\begin{array}{l}0.87 \\
0.71 \\
0.77\end{array}$ & PUR+gel & This paper \\
\hline
\end{tabular}

For vibration, we found the best results (18.4\% lower force) for a relatively slow frequency of $10 \mathrm{~Hz}$. For larger frequencies penetrations forces were higher. This is in contrast to many of the other papers (see table 4 for an overview). However, one study showing lower forces for higher frequencies had the largest marginal reduction in required force going from 0 to $1 \mathrm{~Hz}$, i.e. the smaller frequencies had the largest marginal impact. The skin model could also have a role 
in explaining the differences here but other explanations can be proposed, such as the direction of the vibration and the amplitude. Thixotropy should be expected no matter the direction of the vibration, but for longitudinal vibration the amplitude could have an effect. For larger amplitudes, the effective local stress would be considerably higher when the oscillatory movement is at its one extreme, but the motion is too small to be recorded on the testing equipment, due to the dampening in the skin model.

The statistical testing of measurement results showed significance (p-values below 5\%) when strain and vibration was combined with slow insertion. Significance levels for each of the strategies when viewed alone were between 0.035 and 0.11 , i.e. some of them could not be shown to be statistically significant. A possible reason could be the variance within each of the test series caused by deterioration of the gel in the skin model and the role of injection position.

\section{CONCLUSION}

The present paper presented a number of biological strategies for penetrating skin in a way that causes as little damage as possible to the skin. This includes spines in cactus and porcupines, poisonous spines in caterpillars and bees and specialized mouthparts in ticks and mosquitos. Mosquito strategies are explained and three of them are selected for experimental testing. Skin strain, vibration and insertion velocity are all shown to have an improvement effect on penetration force. Furthermore, it is shown that the effects of the three strategies can be added together, i.e. that they do not affect each other negatively.

\section{REFERENCES}

[1] Lerche, M. H., Jensen, P. R., Karlsson, M.., Meier, S., "NMR Insights into the Inner Workings of Living Cells," Anal. Chem. 87(1), 119-132 (2015).

[2] Schmid, R., Gibson, A. C.., Nobel, P. S., “The Cactus Primer," Taxon 36(1), 297 (1987).

[3] Malainine, M. E., Dufresne, A., Dupeyre, D., Mahrouz, M., Vuong, R.., Vignon, M. R., "Structure and morphology of cladodes and spines of Opuntia ficus-indica. Cellulose extraction and characterisation," Carbohydr. Polym. 51(1), 77-83 (2003).

[4] Mosco, A., "Micro-morphology and anatomy of Turbinicarpus (Cactaceae) spines," Rev. Mex. Biodivers. 80(1) (2009).

[5] Vincent, J. F.., Owers, P., “Mechanical Design of Hedgehog Spines and Porqupine Quills,” J. Zool. 210, 55-75 (1986).

[6] Cho, W. K., Ankrum, J. A., Guo, D., Chester, S. A., Yang, S. Y., Kashyap, A., Campbell, G. A., Wood, R. J., Rijal, R. K., et al., "Microstructured barbs on the North American porcupine quill enable easy tissue penetration and difficult removal," Proc. Natl. Acad. Sci. 109(52), 21289-21294 (2012).

[7] Cho, W. K., Ankrum, J. A., Guo, D., Chester, S. A., Yang, S. Y., Kashyap, A., Campbell, G. A., Wood, R. J., Rijal, R. K., et al., "Microstructured barbs on the North American porcupine quill enable easy tissue penetration and difficult removal.," Proc. Natl. Acad. Sci. U. S. A. 109(52), 21289-21294 (2012).

[8] Ma, G. J., Shi, L. T.., Wu, C. W., "Biomechanical Property of a Natural Microneedle: The Caterpillar Spine," J. Med. Device. 5(3), 34502 (2011).

[9] Ling, J., Jiang, L., Chen, K., Pan, C., Li, Y., Yuan, W.., Liang, L., "Insertion and Pull Behavior of Worker Honeybee Stinger," J. Bionic Eng. 13(2), 303-311 (2016).

[10] Lyimo, I. N.., Ferguson, H. M., "Ecological and evolutionary determinants of host species choice in mosquito vectors," Trends Parasitol. 25(4), 189-196 (2009).

[11] Richter, D., Matuschka, F.-R., Spielman, A.., Mahadevan, L., "How ticks get under your skin: insertion mechanics of the feeding apparatus of Ixodes ricinus ticks," Proc. R. Soc. B Biol. Sci. 280(1773), 2013175820131758 (2013).

[12] Dekker, T., "Selection of biting sites on a human host by Anopheles gambiae s s, An-arabiensis and Anquadriannulatus," Entomol. Exp. Appl. 87(3) (1998).

[13] Kong, X. Q.., Wu, C. W., "Measurement and Prediction of Insertion Force for the Mosquito Fascicle Penetrating into Human Skin,” J. Bionic Eng. 6, 143-152 (2009).

[14] Aoyagi, S., Izumi, H.., Fukuda, M., "Biodegradable polymer needle with various tip angles and consideration on insertion mechanism of mosquito's proboscis," Sensors Actuators, A Phys. 143(1), 20-28 (2008). 
[15] Ramasubramanian, M. K., Barham, O. M.., Swaminathan, V., "Mechanics of a mosquito bite with applications to microneedle design.," Bioinspir. Biomim. 3(4), 1-10 (2008).

[16] Choumet, V., Attout, T., Chartier, L., Khun, H., Sautereau, J., Robbe-Vincent, A., Brey, P., Huerre, M.., Bain, O., "Visualizing Non Infectious and Infectious Anopheles gambiae Blood Feedings in Naive and SalivaImmunized Mice," PLoS One 7(12), e50464 (2012).

[17] Ross, M. H.., Pawlina, W., Histology : a text and atlas : with correlated cell and molecular biology, Wolters Kluwer/Lippincott Williams \& Wilkins Health (2011).

[18] Sakes, A., Dodou, D.., Breedveld, P., "Buckling prevention strategies in nature as inspiration for improving percutaneous instruments: a review," Bioinspir. Biomim. 11(2), 21001, IOP Publishing (2016).

[19] van Gerwen, D. J., Dankelman, J., van den Dobbelsteen, J. J., "Needle-tissue interaction forces - A survey of experimental data," Med. Eng. Phys. 34(6), 665-680, Institute of Physics and Engineering in Medicine (2012).

[20] Mahvash, M.., Dupont, P. E., "Mechanics of dynamic needle insertion into a biological material," IEEE Trans. Biomed. Eng. 57(4), 934-943 (2010).

[21] Hing, J. T., Brooks, A. D.., Desai, J. P., “A biplanar fluoroscopic approach for the measurement, modeling, and simulation of needle and soft-tissue interaction," Med. Image Anal. 11(1), 62-78 (2007).

[22] Crouch, J. R., Schneider, C. M., Wainer, J.., Okamura, A. M., “A velocity-dependent model for needle insertion in soft tissue," Lect. Notes Comput. Sci. (including Subser. Lect. Notes Artif. Intell. Lect. Notes Bioinformatics) 3750 LNCS, 624-632 (2005).

[23] Webster, R. J., Memisevic, J.., Okamura, A. M., "Design Considerations for Robotic Needle Steering," Proc. 2005 IEEE Int. Conf. Robot. Autom. 2005, 3588-3594, IEEE (2005).

[24] Barnes, H. A., “Thixotropy-a review,” J. Nonnewton. Fluid Mech. 70(1-2), 1-33 (1997).

[25] Izumi, H., Suzuki, M., Aoyagi, S.., Kanzaki, T., "Realistic imitation of mosquito's proboscis: Electrochemically etched sharp and jagged needles and their cooperative inserting motion," Sensors Actuators, A Phys. 165(1), 115-123 (2011).

[26] Yang, M.., Zahn, J. D., "Microneedle Insertion Force Reduction Using Vibratory Actuation,” Biomed. Microdevices 6(3), 177-182 (2004).

[27] Muralidharan, K., "Mechanics of soft tissue penetration by a vibrating needle," University of Maryland (2007).

[28] Wildnauer, R. H., Bothwell, J. W.., Douglass, A. B., "Stratum Corneum Biomechanical Properties I. Influence of Relative Humidity on Normal and Extracted Human Stratum Corneum,” J. Invest. Dermatol. 56(1), 72-78 (1971).

[29] Gelita., "Preparation of Gelatine Blocks for Ballistics Testing" (2012). 